\title{
$\mathrm{M}|\mathrm{R}| \mathrm{S}$
}

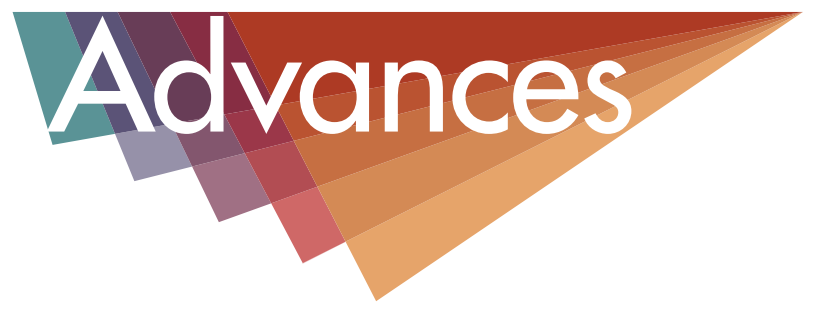

Mechanical

Behavior and

Structural

Materials 


\title{
MRS Advances: Mechanical Behavior and Structural Materials
}

\author{
Associate Editor: \\ Marian Kennedy, Clemson University, USA \\ Principal Editors: \\ Gwan-Hyoung Lee, Seoul National University, Republic of Korea \\ Peter Fratzl, Max Planck Institute of Colloids and Interfaces, Germany
}

\author{
MRS Advances Editorial Board: \\ Editor-in-Chief: David F. Bahr, Purdue \\ University, USA \\ Meenakshi Dutt, Rutgers University, USA \\ Norbert Huber, HZG (Helmholtz-Zentrum \\ Geesthacht Centre for Materials and Coastal \\ Research), Germany \\ Marian Kennedy, Clemson University, USA
}

\author{
Praveen Kumar, Indian Institute of Science, \\ India \\ John Stuart McCloy, Washington State \\ University, USA \\ Ruth Schwaiger, Karlsruhe Institute of \\ Technology, Germany \\ Jeremy Theil, Mountain View Energy, USA
}

Materials Research Society Editorial Office, Warrendale, PA, USA:

Ellen W. Kracht, Publications Manager,

Materials Research Society, Warrendale, PA,

USA

Susan Dittrich, Editorial Associate, Materials

Research Society, Warrendale, PA, USA
Kirby L. Morris, Editorial and Production Associate, Materials Research Society,

Warrendale, PA, USA

Eileen M. Kiley, Director of Communications, Materials Research Society, Warrendale, PA, USA

\begin{abstract}
Disclaimer
Authors of each article appearing in this Journal are solely responsible for all contents in their article(s) including accuracy of the facts, statements, and citing resources. Facts and opinions are solely the personal statements of the respective authors and do not necessarily represent the views of the editors, the Materials Research Society, or Cambridge University Press.
\end{abstract}

MRS Advances (EISSN: 2059-8521) is published by Cambridge University Press, One Liberty Plaza, Floor 20, New York, NY 10006 for the Materials Research Society.

Copyright (C) 2020, Materials Research Society. All rights reserved. No part of this publication $\backsim$ may be reproduced, in any form or by any means, electronic, photocopying, or otherwise, without permission in writing from Cambridge University Press. Policies, request forms and contacts are navailable at: http://www.cambridge.org/rights/permissions/permission.htm. Permission to copy (for users in the USA) is available from Copyright Clearance Center at: http://www.copyright.com, s email: info@copyright.com.

\section{Purchasing Options:}

¿ Premium Subscription- Premium Subscription includes current subscription and one year's lease zaccess to the full MRS Online Proceedings Library Archive for \$7,219.00 / £4,888.00 / €6,647.00.

Subscription-Subscription with perpetual access to the content subscribed to in a given year, including ¿ three years of back-file lease access to content from the MRS Online Proceedings Library Archive. The price for a 2018 subscription is $\$ 3,019.00$ / £1,948.00 / €2,625.00. MRS Members-Access to MRS Advances is available to all MRS members without charge.

\section{Contact Details:}

For all inquiries about pricing and access to MRS Advances, please get in touch via the following email addresses: online@cambridge.org (for the Americas); library.sales@cambridge.org (for UK, Europe, and rest of world). 


\section{CONTENTS}

\section{ARTICLES}

\section{Fatigue Behavior of A Minor Yttrium Doped}

ZrCuNi-Based Metallic Glass Alloy Fabricated by

Industrial Grade Raw Material ................. 1713

Shichao Zhou, Tao Zhang, Min Zhang and Yong Zhang

Carbon Nanotube Peapods Under High-Strain Rate

Conditions: A Molecular Dynamics Investigation ........ 1723

J. M. De Sousa, C. F. Woellner, L. D. Machado,

P. A. S. Autreto and D. S. Galvao

Zero-Dimensional Graphene and Its Behavior underMechanochemical Activation with Zinc Ferrite

Nanoparticles

Monica Sorescu, Matthew Knauss, Alice Perrin

and Michael McHenry

A Three Dimensional Unit Cell Model for the Analysis of Thermal Residual Stresses in Polymer Composites

Reinforced with Wavy Carbon Nanotubes............. 1739

Y. Zhang, A. Johnston, A. Yousefpour, J. Guan, B. Simard and C. Kingston

Interfacial Study on the Functionalization of Continuously

Exfoliated Graphite in a PA66 Using High Shear

Elongational Flow .......................... 1749

Justin W. Hendrix, Thomas Nosker, Jennifer Lynch-Branzoi

and Thomas Emge

Multifunctional hybrid sol-gel coatings for Marine

Renewable Energy Applications: Synthesis,

Characterization and Comparative Analysis with

Organically Modified Silicon Precursor Coatings ......... 1757

Manasa Hegde, Yvonne Kavanagh, Brendan Duffy

and Edmond F. Tobin

Dependence of bonding strength and variations in residual stress on interface wedge angles and bonding temperature conditions .............................. 1765

Shunsuke Muraoka and Masayoshi Tateno 
Mechanical Properties of Diamond Schwarzites: From

Atomistic Models to 3D-Printed Structures . . . . . . . . . . . 1775

Levi C. Felix, Vladimir Gaál, Cristiano F. Woellner, Varlei Rodrigues and Douglas S. Galvao

Towards the Development of a Cartilage-like NanofiberHydrogel Composite ....................... 1783 Jacob M. Ludwick and Michelle L. Oyen

Fabrication and Characterization of Porous Silica/Carbon

Nanotube Composite Insulation ................. 1791

Naoto Shioura, Kazuki Matsushima, Tomoki Osato,

Tomonaga Ueno, Norifumi Isu, Takeshi Hashimoto

and Takumi Yana

Analysis of Burnup effects and Its Integrity Assessment in the Interim of Irradiation with Molecular Dynamics. . . . . . . 1799

Ahli K.D. Willie, Hongtao Zhao, M. Mustafa Azeem and Teplinskaya Svetlana

The effect of dislocation nature on the size effect in Indium Antimonide above and below the brittle-ductile transition............................. 1811

J.M. Wheeler, L. Thilly, Y. Zou, A. Morel, R. Raghavan and J. Michler 